\title{
Pelatihan Senam Hamil pada Ibu Hamil di RT03/RW01 Desa Labuhan Tangga Hilir Kecamatan Rokan Hilir
}

\author{
Sara Herlina ${ }^{1}$; Dewi Sartika Siagian ${ }^{2}$; Nurmaliza ${ }^{3 *}$; Siti Qomariah ${ }^{4}$; Wiwi Sartika ${ }^{5}$; \\ Rini Hariani Ratih ${ }^{6}$ \\ Published online: 5 July 2021
}

\begin{abstract}
During pregnancy, the mother experiences physical and psychological / emotional changes in the pregnant woman. During pregnancy, emotions easily fluctuate and rise, which occurs due to hormonal changes. As for the anxiety before childbirth, pregnant women will appear statements and images of whether they can give birth normally, how to push, whether something will happen during childbirth, or whether the baby is born safely, will increasingly appear in the mother's mind, this condition can cause further anxiety and tension to form a feedback cycle that can increase overall emotional intensity. To break the cycle of anxiety, pregnancy exercise as a prenatal service is an alternative therapy that can be given to pregnant women. The purpose of this service is to increase the knowledge of mothers and do structured pregnancy exercises. The method in this service is pregnancy exercise counseling and pregnancy exercise training. The result of this community service is that it is known that $60 \%$ of participants have a pretest score of $<65$ about pregnancy exercise and after an explanation, $80 \%$ of the participants get a score of $>65$. The results of pregnancy exercise training, the majority of mothers did pregnancy exercises at home and there was a reduction in low back and back pain as much as $66.6 \%$. Conclusion: Based on the results of pregnancy exercise counseling, there was an increase in knowledge seen from the pre and post test scores, namely from $40 \%$ to $80 \%$ and pregnant women also did pregnancy exercises at home and there was a reduction in pain as much as $66.6 \%$.
\end{abstract}

Keyword: Training, gymnastics, pregnant women

\begin{abstract}
Abstrak. Selama kehamilan, ibu mengalami perubahan fisik dan kejiwaan/emosi ibu hamil. Pada masa kehamilan, emosi mudah turun dan naik, yang terjadi akibat perubahan hormon. Adapun kecemasan menjelang pesalinan ibu hamil akan muncul pernyataan dan bayangan apakah dapat melahirkan normal, cara mengejan, apakah akan terjadi sesuatu saat melahirkan, atau apakah bayi lahir selamat, akan semakin muncul dalam benak ibu, kondisi ini dapat menyebabkan kecemasan dan ketegangan lebih lanjut sehingga membentuk suatu siklus umpan balik yang dapat meningkatkan intensitas emosional secara keseluruhan. Untuk memutuskan siklus kecemasan tersebut, maka senam hamil sebagai salah satu pelayanan prenatal, merupakan suatu alternatif terapi yang dapat diberikan pada ibu hamil. Tujaun Pengabdian ini adalah untuk menambah pengetahuan ibu dan melakukan senam hamil yang terstruktur. Metode dalam pengabdian ini adalah ceramah senam hamil dan pelatihan senam hamil. Hasil pengabdian kepada masyarakat ini adalah diketahui bahwa $60 \%$ peserta memiliki nilai pretest $<65$ tentang senam hamiln dan setelah dilakukan penjelasan sebanyak $80 \%$ peserta mendapatkan nilai $>65$. Hasil pelatihan senam hamil mayoritas ibu melakukan senam hamil dirumah dan terjadi pengurangan nyeri pinggang dan punggung sebanyak 66,6\%. Kesimpulan: Berdasarkan hasil penyuluhan senam hamil terjadi peningkatan pengetahuan dilihat dari nilai pre dan post tes yaitu dari $40 \%$ menjedi $80 \%$ dan ibu hamil juga melakukan senam hamil dirumah dan terjadi pengurangan nyeri sebanyak $66,6 \%$.
\end{abstract}

Kata kunci: Pelatihan, Gimnastik, Perempuan Hamil

\footnotetext{
${ }^{1-6}$ Universitas Abdurrab

*) corresponding author
}

Nurmaliza

Fakultas Farmasi dan Ilmu Kesehatan Universitas Abdurrab, Pekanbaru, Indonesia

Email: nurmaliza@univrab.ac.id

\section{PENDAHULUAN}

Selama kehamilan, ibu mengalami perubahan fisik dan kejiwaan/emosi ibu hamil. Pada masa kehamilan, emosi mudah turun dan naik, yang terjadi akibat perubahan hormon. Adapun 
kecemasan menjelang pesalinan ibu hamil akan muncul pernyataan dan bayangan apakah dapat melahirkan normal, cara mengejan, apakah akan terjadi sesuatu saat melahirkan, atau apakah bayi lahir selamat, akan semakin muncul dalam benak ibu, kondisi ini dapat menyebabkan kecemasan dan ketegangan lebih lanjut sehingga membentuk suatu siklus umpan balik yang dapat meningkatkan intensitas emosional secara keseluruhan. Untuk memutuskan siklus kecemasan tersebut, maka senam hamil sebagai salah satu pelayanan prenatal, merupakan suatu alternatif terapi yang dapat diberikan pada ibu hamil (Muhimah, 2010).

Senam hamil merupakan cara yang mendukung kemudahan dalam persalinan dan membantu memberikan relaksasi terhadap kehamilan trimester III. Senam hamil bertujuan mempersiapkan dan melatih otot-otot sehingga dapat berfungsi secara optimal dalam persalinan normal. Senam dapat mengurangi berbagai gangguan yang umumnya terjadi selama kehamilan seperti varises, sakit pinggang serta nyeri otot dan persendian, meningkatkan stamina yang sangat diperlukan selama persalinan dan menguatkan serta mengencangkan otot yang paling banyak mempengaruhi dalam kehamilan: otot pelvis, otot perut dan otot pinggang (Manuaba, 2009). Pelatihan senam hamil merupakan upaya untuk melakukan pembinaan kepada ibu hamil agar mereka dapat mengatasi katidak nyamanan pada masakehamilan terutanya nyeripunggung dan pinggang serta mengurangi rasa kecemasan dalam menghadapi persalinan, tidak pernah dilakukan senam hamil, dan adanya wabah covid $19 \mathrm{ibu}$ hamil tidak bisa datang kepelayanan kesehatan.

Menurut penelitian Yosefa, et all (Febriana, Yosefa, Misrawati, Yesi, 2014). Hasil penelitian menunjukkan bahwa pemberian senam hamil pada kelompok eksperimen menurunkan intensitas nyeri punggung pada ibu hamil dengan selisih nilai rata-rata intensitas nyeri sebesar 2,40 dan berdasarkan hasil uji wilcoxon menunjukkan signifikansi dengan nilai $\mathrm{p}(0,000)<\alpha(0,05)$. Pada kelompok control terjadi penurunan intensitas nyeri namun tidak signifikan dengan selisih rata-rata intensitas nyeri sebesar 0,47 dan berdasarkan hasil uji wilcoxon menunjukkan tidak signifikan dengan nilai $p(0,159)>\alpha(0,05)$. Hasil uji t independent dimana diperoleh $p(0,001)<\alpha(0,05)$. Hal ini berarti terdapat perbedaan yang signifikan antara rata-rata intensitas nyeri punggung ibu hamil pada kelompok eksperimen dan kelompok control sesudah diberikan senam hamil, dengan demikian dapat disimpulkan bahwa senam hamil efektif terhadap penurunan nyeri punggung pada ibu hamil.

Berdasarkan hasil penelitian Fitriani, 2018. Menggunakan uji t-test terdapat penurunan skala nyeri sebelum dan sesudah senam hamil dengan total nilai rata-rata penurunan yaitu 26 dan nilai p.value 0,000 yang artinya Ho ditolak berarti ada hubungan yang bermakna antara ibu hamil yang melakukan senam hamil dengan penurunan nyeri punggung.

Pelaksanaan kegiatan pengabdian kepada masyarakat dilakukan bekerjasama dengan ketua RT03 desa labuhan tangga hilir. Hasil pertemuan dan diskusi dengan mitra disepakati upaya pemecahan masalah akan dilakukan dengan menggunakan pendekatan strategi five level of prevention, yang merupakan pencegahan tingkat I. Kegiatannya meliputi (1) solusi untuk pengurangi rasa ketidak nyamanan dan kecemasan adalah penjelasan atau penyuluhan tentang senam hamil guna mengurangi ketidaknyamanan dalam kehamilan, (2) solusi untuk tidak bisa datang kepelayanan kesehatan karena wabah covid 19 dan lokasi nakes jauh maka dilakukan pelatihan senam hamil yang nantinya ibu bisa melakukannya sendiri dirumah masing-masing. Tujuan Pengabdian ini adalah untuk menambah pengetahuan ibu tentang senam hamil dan memotivasi ibu agar melakukan senam hamil yang terstruktur guna mempersiapkan persalinan lancar dan normal.

\section{SOLUSI DAN TARGET}

\begin{tabular}{|l|l|l|l|}
\hline No & Permasalahan & Akar Masalah & Solusi yang disepakat \\
\hline 1 & $\begin{array}{l}\text { Nyeri pinggang dan punggung serta } \\
\text { kecemasan menghadapi persalinan }\end{array}$ & $\begin{array}{l}\text { Pengetahuan fisiologi kehamilan } \\
\text { yang rendah }\end{array}$ & $\begin{array}{l}\text { Penyuluhan atau penjelasan } \\
\text { tentang keluan ibu hamil }\end{array}$ \\
\hline 2 & Jauhnya layanan kesehatan & $\begin{array}{l}\text { Tidak perta ada pelatihan senam } \\
\text { hamil }\end{array}$ & Pelatihan senam hamil \\
\hline
\end{tabular}




\section{METODE PELAKSANAAN}

Adapun metode kegiatan yang dipergunakan dalam pengabdian masyarakat ini adalah ceramah dan langsung praktek senam ibu hamil. Tahap pertama ceramah: Merupakan upaya yang dilakukan dengan tujuan untuk memberikan kesadaran kepada mitra. Kegiatan yang dilakukan adalah penyuluhan senam hamil. Tahap kedua praktik senam hamil: Merupakan upaya yang dilakukan dengan tujuan untuk memastikan mitra mengadopsi konsep secara mandiri. Kegiatan yang dilakukan adalah praktek senam hamil. Teknik Penyelesaian Masalah: Untuk mengatasi permasalahan tersebut maka tim akan melakukan upaya pencegahan tingkat I sebelum sasaran mengalami kecemasan. Tahapan yang dilakukan oleh tim agar ibu hamil menjadi tahu, mau dan mampu menerapkan upaya menghilangkan rasa cemas dalam menghadapi persalinan meliputi tahapan sadar, tertarik, uji coba, evaluasi, dan adopsi konsep.Penggunaan prinsip ini memungkinkan mitra mengetahui, menemukan dan menyadari sendiri kekurangan serta kesalahan yang dilakukan, sehingga solusi yang diberikan melalui transfer pengetahuan merupakan solusi yang benar-benar sesuai dengan kebutuhan oleh mitra. Melalui proses seperti ini diharapkan inovasi yang diberikan memiliki tingkat keberlanjutan yang tinggi dan menjadi kebiasaan yang dilakukan oleh mitra. Upaya penyadaran dilakukan dengan penyampaian informasi melalui (1) penjelasan materi untuk memberikan pemahaman kepada mitra, (2) pelatihan senam hamil. Mitra melakukan secara mandiri untuk memastikan mitra melakukan perubahan perilaku dengan benar. Secara garis besar proses yang dilakukan agar mitra tahu, mau dan mampu melaksanaan kegiatan ini, digambarkan sebagai berikut:

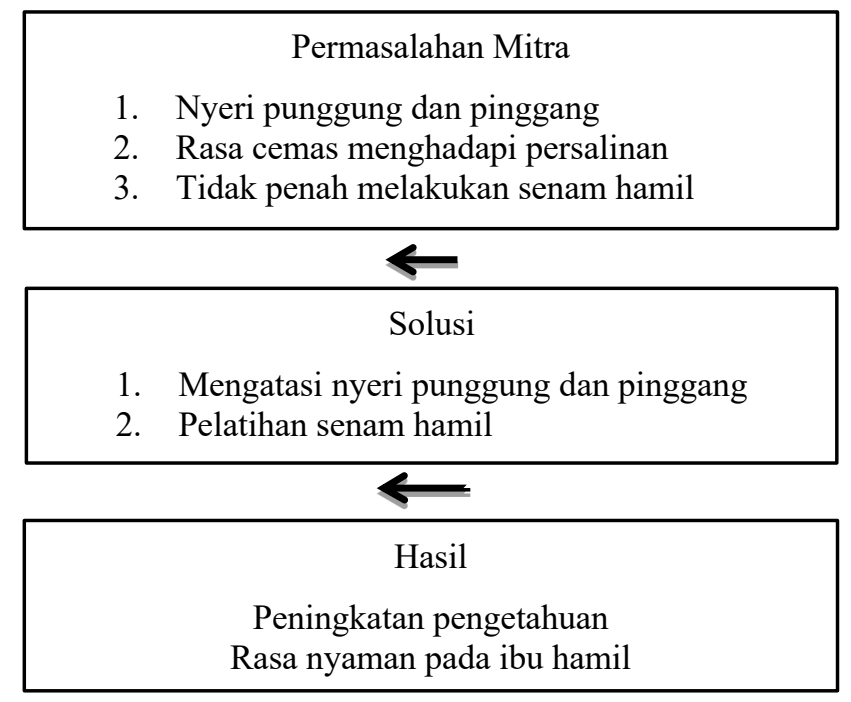

\section{PELAKSANAAN KEGIATAN}

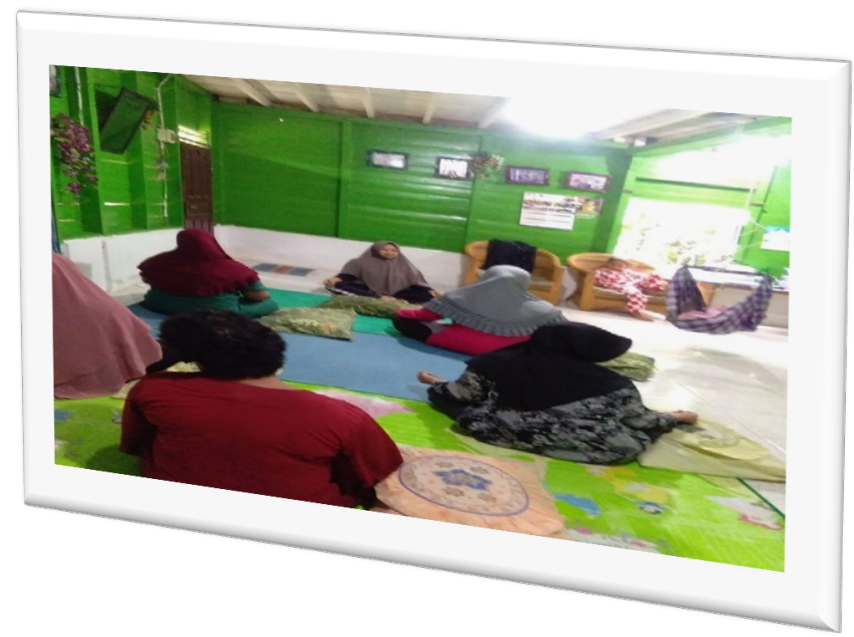

Gambar 1. Kegiatan penyuluhan 


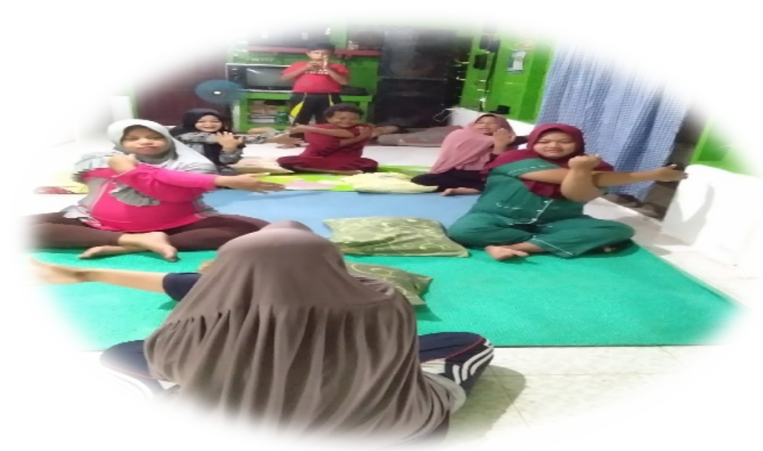

Gambar 2. Kegiatan praktik senam hamil

\section{HASIL DAN PEMBAHASAN}

Kegiatan pengabdian masyarakat kunjungan pertama telah dilakukan pada hari Kamis tanggal 21Mei 2020 yang diadakan RT 03/ RW 01 Desa labuhan tangga hilir dengan jumlah peserta 5 orang dan knjungan ke dua dilaksanakan pada hari kamis tanggal 28 Mei 2020.

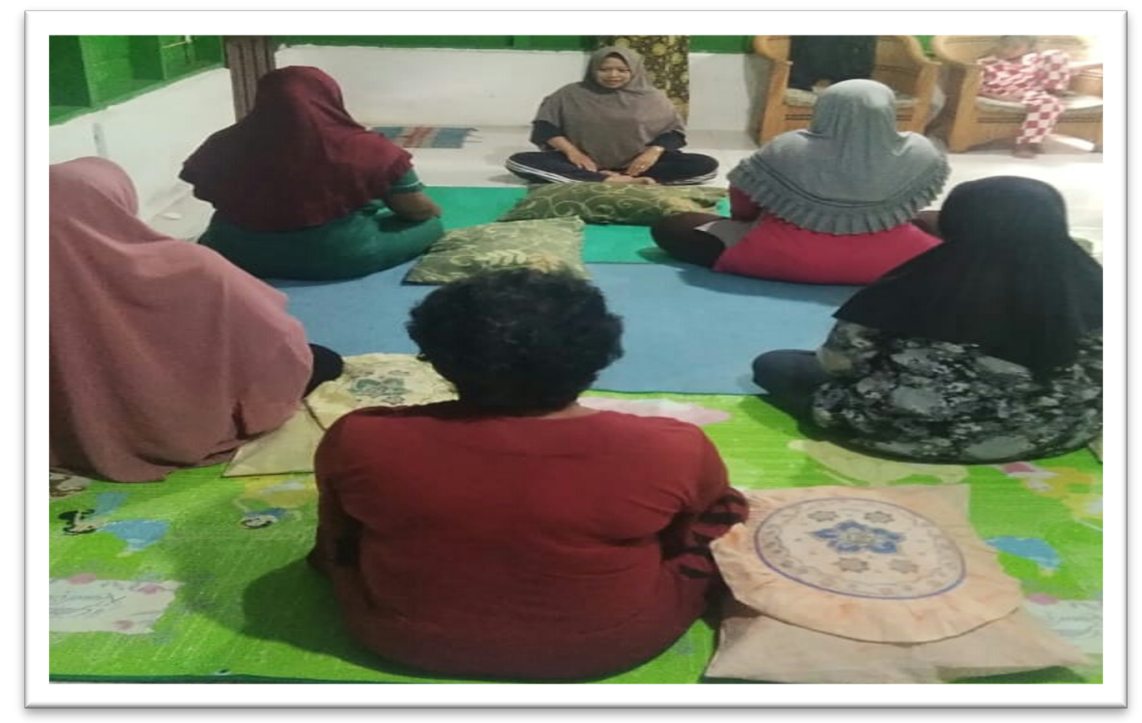

Gambar 3. Penyuluhan senam hamil

Saat dilakukan penjelasan tentang senam hamil ibu-ibu hamil sangat berantusias dalam mendengarkan penjelasan yang diberikan terutama pada manfaat senam hamil. Ibu hamil juga banyak bertanya tentang senam hamil. Terjadi perubahan pengetahuan pada ibu hamil tentang senam hamil hal ini dapat dilihat pada tabel berikut.

Tabel 1. Nilai pre test dan post-test pengetahuan ibu hamil $(\mathrm{N}=5)$.

\begin{tabular}{cccccc}
\hline \multicolumn{7}{c}{ pengetahuan ibu hamil } \\
\hline Nilai pre test & $\mathbf{n}$ & $\mathbf{\%}$ & Nilai post test & n & \% \\
\hline$<65$ & 3 & 60 & $<65$ & 1 & 20 \\
\hline$>65$ & 2 & 40 & $>65$ & 4 & 80 \\
\hline
\end{tabular}

Berdasarkan tabel 1 diketahui bahwa $60 \%$ peserta memiliki nilai pretest $<65$ tentang senam hamil. Setelah dilakukan penjelasan sebanyak $80 \%$ peserta mendapatkan nilai $>65$. Dari tabel 1 dan 2 dapat dilihat bahwa terdapat peningkatan pengetahuan peserta tentang senam hamil. Dimana nilai $>65$ mengalami peningkatan dari $40 \%$ menjadi $80 \%$. 

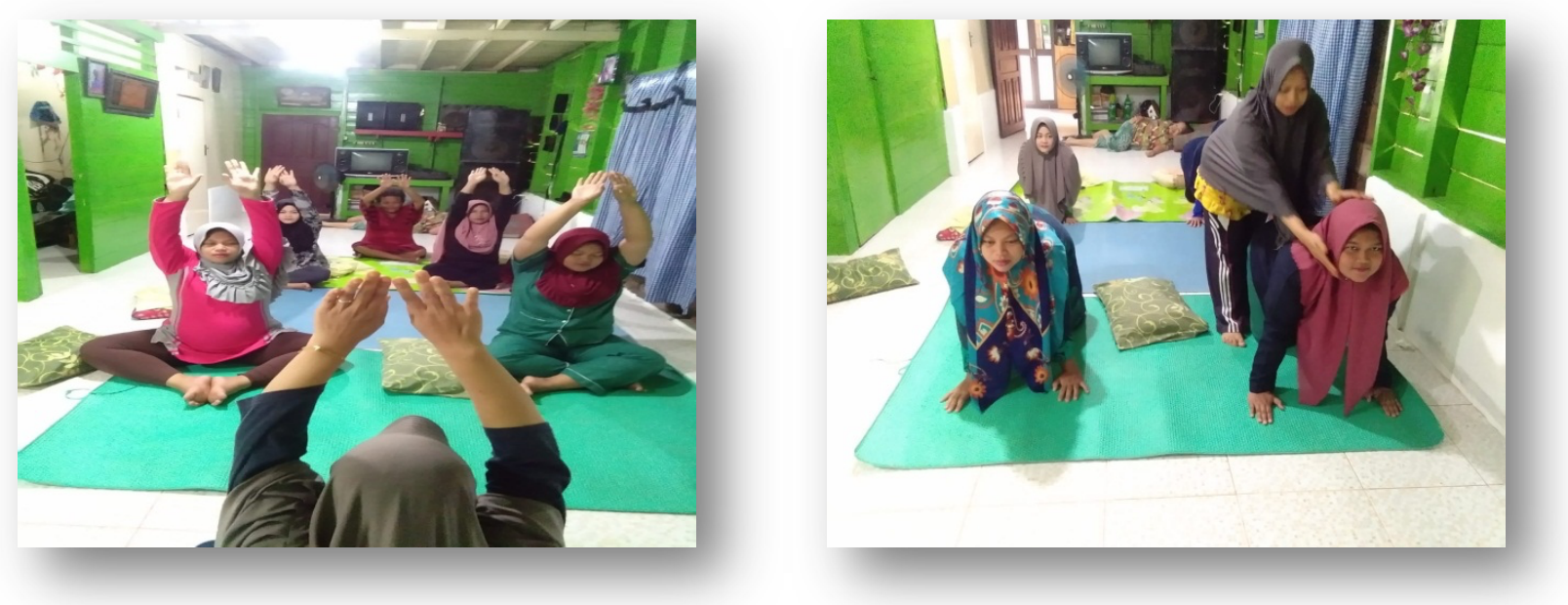

Gambar 4. Praktek senam hamil

Kegiatan selanjutnya adalah melakukan demonstrasi senam hamil. Ibu hamil sangat semangat saat melakukan senam hamil. Hal ini dapat dilihat ketika demostrasi berlangsung beberapa ibu hamil meminta untuk mengulangi beberapa gerakan yang mereka kurang faham. Pada kunjungan ke dua saat dilakukan evaluasi ibu hamil sudah hafal dengan gerakan-gerakan saat dilakukan demonstrasi pada pertemuan pertama. Ibu hamil juga melakukan senam hamil secara rutin di rumah masingmasing. Ibu hamil bersemangat karena dengan melakukan senam hamil proses persalinannya berjalan lancar. Berdasarkan wawancara kepada 3 orang ibu hamil yang mengalami nyeri pinggang dan punggung 2 orang ibu hamil $(66,6 \%)$ selama mereka rutin melakukan senam hamil rasa nyeri pinggang dan punggung yang dialami ibu sudah mulai berkurang.

Senam hamil dapat meringankan keluhan nyeri punggung yang dirasakan oleh ibu hamilkarena didalam senam hamil terdapat gerakanyang dapat memperkuat otot abdomen. Fungsipenting dari otot abdomen yaitu kontrol pelvissaat menengadah. Ketika ligamen disekitar pelvismenegang dan tidak lagi memberikan topanganyang kuat kepada sendi maka otot menjadi garispertahanan kedua membantu mencegah teganganyang berlebihan pada ligamen pelvis. Harusdiingat bahwa tegangan yang berlebihan padapelvis dan melemahnya otot abdomen inilah yangmenyebabkan nyeri punggung. Untuk itu perludilakukan latihan ini untuk mempertahankantonus otot abdomen yang baik (Myles, 2009).

Berdasarkan hasil penelitian Fitriani, 2018. Menggunakan uji t-test terdapat penurunan skala nyeri sebelum dan sesudah senam hamil dengan total nilai rata-rata penurunan yaitu 26 dan nilai p.value 0,000 yang artinya Ho ditolak berarti ada hubungan yang bermakna antara ibu hamil yang melakukan senam hamil dengan penurunan nyeri punggung.

Menurut penelitian yang dilakukan oleh (Puspitasari, 2013) tentang hubungan senam hamil dengan nyeri punggung pada ibu hamil di Rumah Sakit Kendangsari Surabaya dengan hasil $p$ value $=0,000$ yang artinya Ho ditolak artinya adanya hubungan yang bermakna antara ibu hamil yang melakukan senam hamil dengan nyeri punggung. Semakin teratur mengikuti senam hamil maka hal ini dapat meminimalkan nyeri punggung yang dirasakan oleh ibu hamil.

\section{KESIMPULAN DAN SARAN}

Berdasarkan hasil penyuluhan tentang senam hamil terjadi peningkatan pengetahuan dilihat dari nilai pre dan post tes yaitu dari $40 \%$ menjedi $80 \%$. Hasil praktek senam hamil mayoritas ibu melakukan senam hamil dirumah dan terjadi pengurangan nyeri pinggang dan punggung sebanyak $66,6 \%$. 


\section{PENGAKUAN}

1. Kepada Seluruh jajaran Universitas Abdurrab yang telah mendukung proses kegitan Pengabdian masyarakat ini sampai selesai dan berjalan lancar

2. Kepada Bapak RT yang sudah memberikan izin pengabdian ini sampai selesai

3. Kepada Ibu-ibu hamil yang sudah bersedia untui mengikuti kegiatan pengabdiani masyarakat ini sampai selesai

4. Kepada teman-teman yang sudah terlibat baik secara langsung maupun tidak langsung.

\section{Conflict of Interests}

The authors declared that no potential conflicts of interests with respect to the authorship and publication of this article.

\section{DAFTAR PUSTAKA}

Febriana, Yosefa, Misrawati, Yesi, H. (2014). No Title. C Jurnal Online Mahasiswa Program Studi Ilmu Keperawatan Universitas Riau. https:/www.neliti.com/id/publications/189233/efektifitassenam-hamil-terhadap-penurunan-nyeri-punggung-pada-ibu-hamil

Manuaba. (2009). Konsep Obstetri dan Ginekologi Sosial Indonesia. EGC.

Muhimah, N. dan S. (2010). Panduan Lengkap Senam Hamil, Khusus Ibu Hamil. Power Book. Myles. (2009). Buku Ajar Bidan. EGC.

Puspitasari, A. R. (2013). Hubungan senam hamil dengan nyeri punggung pada ibu hamil trimester III. StikesYarsi. 